Check for updates

Cite this: RSC Adv., 2019, 9, 13863

Received 4th April 2019

Accepted 23rd April 2019

DOI: 10.1039/c9ra02531f

rsc.li/rsc-advances

\section{Facile one-pot synthesis of sulfonyl fluorides from sulfonates or sulfonic acids $\uparrow$}

\author{
Ying Jiang, ${ }^{a}$ Njud S. Alharbi, ${ }^{b}$ Bing Sun ${ }^{* a}$ and Hua-Li Qin (D)*a \\ A facile cascade process for directly transforming the abundant and inexpensive sulfonates (or sulfonic \\ acids) to the highly valuable sulfonyl fluorides was developed. This new protocol features mild reaction \\ conditions using readily available and easy-to-operate reagents. A diverse set of sulfonyl fluorides was \\ prepared facilitating the enrichment of the sulfonyl fluoride library.
}

Sulfonyl fluorides (SFs) have been identified and utilized in the realms of biology, pharmaceuticals and functional molecules for their unique stability-reactivity balance. ${ }^{1}$ Owing to the relatively low reactivity toward nucleophilic substitution and the exclusive heterolytic property, SF electrophiles are privileged motifs in the selective covalent interaction with context-specific amino acids or proteins for diverse applications (Fig. 1). ${ }^{2}$ For example, Murthy and co-workers disclosed that 2-nitrobenzenesulfonyl fluoride (NBSF, Fig. 1) was effective at killing Gram-negative bacteria, where the SF group could possibly react with target proteins directly or via an intermediate. ${ }^{3}$ By holding a compatible electrophilicity, SFs have found remarkable utility as covalent probes in chemical biology, which enable the efficient targeting of active-site amino acid residues. ${ }^{2,4}$ Meanwhile, through the reaction of SFs with active site amino acids to

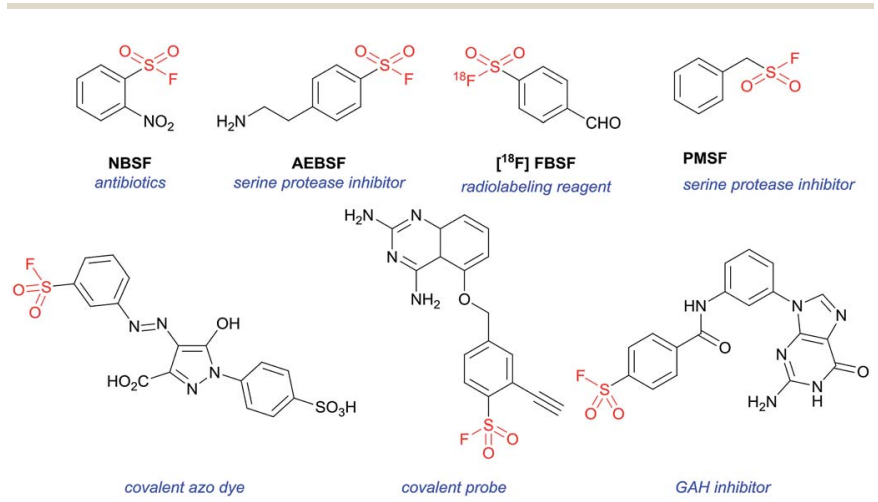

Fig. 1 Representative sulfonyl fluoride-containing molecules with significant biological values.

${ }^{a}$ School of Chemistry, Chemical Engineering and Life Sciences, Wuhan University of Technology, Wuhan 430070, P. R. China.E-mail: bing.sun@whut.edu.cn; qinhuali@ whut.edu.cn

${ }^{b}$ Biotechnology Research Group, Deportment of Biological Sciences, Faculty of Science, King Abdulaziz University, Jeddah, Saudi Arabia. E-mail: njud_alharbi@yahoo.com $\dagger$ Electronic supplementary information (ESI) available. See DOI: 10.1039/c9ra02531f inactivate these enzymes, the corresponding SF-type protease inhibitors could be developed. ${ }^{5}$ The commonly used serine protease inhibitors include (2-aminoethyl)benzenesulfonyl fluoride (AEBSF, Fig. 1), of which the hydrochloride salt is called Pefabloc $\AA^{5 a, c}$ In addition, the diagnostic value of SF in ${ }^{18} \mathrm{~F}$ labelled biomarkers in positron emission tomography has also drawn much attention, such as the application of $\left[{ }^{18} \mathrm{~F}\right] 4$ formylbenzenesulfonyl fluoride $\left(\left[{ }^{18} \mathbf{F}\right] \mathbf{F B S F}\right.$, Fig. 1) as a radio labeling synthon. ${ }^{6}$

Despite the versatile findings on the utility of SFs, the efforts toward their synthesis often encountered sluggishness. The most common method involves a chlorine-fluorine exchange of arenesulfonyl chloride in the presence of aqueous solution of $\mathrm{KF}^{7}$ or $\mathrm{KHF}_{2}$ (ref. 8) (Scheme 1a). A more efficient system could be achieved with phase transfer catalyst including KF and 18crown-6-ether in acetonitrile. ${ }^{9}$ However, the generated sulfonyl chloride intermediates as very reactive electrophiles, are easily subjected to nucleophilic attack without selectivity thus are considered as poor candidates in the synthetic sequence of complex molecules. To alleviate this issue, a pd-catalysed strategy through the insertion of $\mathrm{SO}_{2}$ to $\mathrm{Ar}-\mathrm{X}$ for assembly of $\mathrm{ArSO}_{2} \mathrm{~F}$ was introduced (Scheme 1b). ${ }^{10}$ As a continuation of our search for general and practical protocols for the synthesis of sulfonyl fluoride motifs, ${ }^{11}$ we attempted to use the stable and readily available sulfonates as starting material. In fact, a successful exploration on sulfonate as raw material has been conducted by Sharpless and co-workers, unveiling a two-step synthesis of SFs comprising the initial preparation of sulfonyl chloride by reacting sulfonate with chlorosulfuric acid, and subsequent chlorine-fluorine exchange to form $\mathrm{S}^{\mathrm{VI}}-\mathrm{F},{ }^{1 a}$ whereas the use of toxic chlorosulfuric acid inevitably raises the safety risk. On the other hand, DAST (diethyl amino sulfur trifluoride), XtalFluor-M

(difluoro-4-morpholinylsulfonium'tetrafluoroborate) and related reagents were also reported for fluorination reactions, however, these reagents have rarely been successfully applied for the synthesis of sulfonyl fluorides. ${ }^{12 a, b}$ Comparing with DAST, $\mathrm{KHF}_{2}$ is an inexpensive, stable, and industrially applicable chemical acting as both nucleophile and buffer for the preparation of sulfonyl fluorides. ${ }^{12 c, d}$ Herein, we 
(a) Chlorine-fluorine exchange strategy

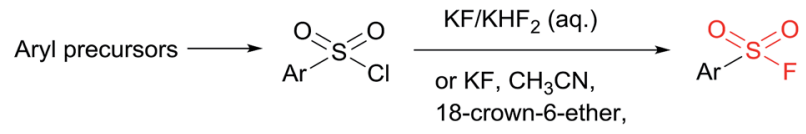

(b) Transition metal catalysis strategy

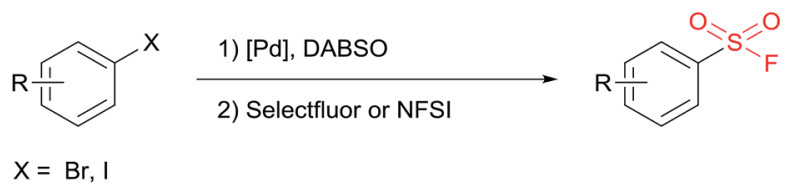

(c) One-pot synthesis of SF (this work)

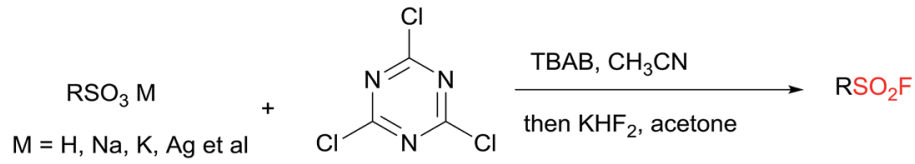

Scheme 1 Strategies for the assembly of sulfonyl fluorides.

report the transition-metal-free one-pot synthesis of SFs from sulfonates in the presence of cyanuric chloride and $\mathrm{KHF}_{2}$ (Scheme 1c). Phase transfer catalyst tetra- $n$-butylammonium bromide (TBAB) was selected for the transformation of sulfonates, while tetramethylammonium chloride (TMAC) was used for the case of sulfonic acid.

The preparations of SFs from sulfonate salts ${ }^{1 a, 13,14}$ are rarely reported and could date back to Kulka's work over sixty years ago (or even earlier), and therein chlorosulfuric acid (occasionally oxalyl chloride) is essential for the provisional forming of $\mathrm{S}^{\mathrm{VI}}$-Cl, followed by chlorine-fluorine transformation in a separated step to produce $\mathrm{S}^{\mathrm{VI}}-\mathrm{F}$. The chlorination process is regarded as the pivotal step, which normally requires harsh conditions. From a practical point of view, the convenient handling of the stable and nontoxic raw materials is particularly advantageous. Therefore, our focus is addressed on the efficient transformations of sulfonate with readily available and easyhandling reagents to install SF group. Cyanuric chloride (2) is usually used as an alternative to oxalyl chloride in the Swern oxidation, ${ }^{15}$ which may also be effective in the preparation of sulfonyl chloride. To verify this hypothesis, our preliminary study was set out for reaction condition screening (Table 1). Various quaternary ammonium salts, such as tetrabutylammonium iodide (TBAI), tetrabutylammonium acetate (TBAA), tetramethylammonium chloride (TMAC) and TBAB, were tested as catalysts for the reaction of sodium 4-methylbenzenesulfonate (1a) with 2 in acetonitrile (entries 1-7, Table 1). The addition of reagents was divided into two steps according to the reaction nature. Notably, the fluorine source was introduced directly after quenching the system to room temperature without any additional separation or purification. The maximum HPLC yield of $74 \%$ were observed for TBAB with a broad range of amount $(5.0 \%$ to $20 \%)$. Interestingly, when the single solvent acetonitrile was replaced with dual-solvent of acetonitrile and acetone $(1: 1 \mathrm{v}: \mathrm{v}$ ), the yield of 3a was improved to $86 \%$ (entry 8 , Table 1). In spite of the significant promotion effect of "on water" phenomenon for bifluoride-involved fluorination proposed by Sharpless, ${ }^{16}$ it seems that the present system is also feasible (the detailed study of solvent screening can be found in ESI $†$ ). Then, a series of fluoride salts as $\mathrm{F}^{-}$source were screened. To be expected, potassium bifluoride showed superior activity compared to other fluoride salts (entries 8-11, Table 1), which may be attributed to the strong nucleophilicity of the bifluoride anion $[\mathrm{F}-\mathrm{H}-\mathrm{F}]^{-}$, but a minimum amount of $5 \mathrm{~mol} \%$ was required (entries 12-14, Table 1). Thus, it can be concluded that the optimal condition refers to $5 \mathrm{~mol} \%$ of TBAB, 3.0 equivalent of $\mathrm{KHF}_{2}$, acetonitrile/acetone ( $\left.\mathrm{v}: \mathrm{v} \quad 1: 1\right), 1.1$

Table 1 Reaction condition screening ${ }^{a}$

\begin{tabular}{|c|c|c|c|}
\hline & 2 & $\begin{array}{c}\text { cat., } \mathrm{CH}_{3} \mathrm{CN}, 60^{\circ} \mathrm{C}, 12 \mathrm{~h} \\
\text { then }{ }^{-} \mathrm{F} \text { source, acetone, } \\
\text { r.t., } 12 \mathrm{~h}\end{array}$ & \\
\hline Entry & Cat. (mol\%) & $\mathrm{F}^{-}$(eq.) & Yield (\%) \\
\hline $1^{b}$ & TBAI (20) & $\mathrm{KHF}_{2}(5.0)$ & 12 \\
\hline $2^{b}$ & TBAA (20) & $\mathrm{KHF}_{2}(5.0)$ & 17 \\
\hline $3^{b}$ & TMAC (20) & $\mathrm{KHF}_{2}(5.0)$ & 70 \\
\hline $4^{b}$ & TBAB (20) & $\mathrm{KHF}_{2}(5.0)$ & 74 \\
\hline $5^{b}$ & TBAB (10) & $\mathrm{KHF}_{2}(5.0)$ & 74 \\
\hline $6^{b}$ & TBAB (5.0) & $\mathrm{KHF}_{2}(5.0)$ & 74 \\
\hline $7^{b}$ & TBAB (3.0) & $\mathrm{KHF}_{2}(5.0)$ & 60 \\
\hline 8 & TBAB (5.0) & $\mathrm{KHF}_{2}(5.0)$ & 86 \\
\hline 9 & TBAB (5.0) & CsF (5.0) & $<10$ \\
\hline 10 & TBAB (5.0) & $\mathrm{KF}(5.0)$ & 82 \\
\hline 11 & TBAB (5.0) & $\mathrm{CuF}_{2}(5.0)$ & Trace \\
\hline 12 & TBAB (5.0) & $\mathrm{KHF}_{2}(8.0)$ & 87 \\
\hline 13 & TBAB (5.0) & $\mathrm{KHF}_{2}(3.0)$ & 86 \\
\hline 14 & TBAB (5.0) & $\mathrm{KHF}_{2}(2.0)$ & 58 \\
\hline
\end{tabular}

${ }^{a}$ Reaction conditions: $1 \mathrm{a}(0.2 \mathrm{mmol}), 2$ ( $0.22 \mathrm{mmol}, 1.1$ eq.), $\mathrm{CH}_{3} \mathrm{CN}$ (1.0 $\mathrm{mL})$, acetone $(1.0 \mathrm{~mL})$. Yields were determined by HPLC using 4methylbenzenesulfonyl fluoride (3a) as the external standard. ${ }^{b} \mathrm{CH}_{3} \mathrm{CN}(2.0 \mathrm{~mL})$ as the single solvent. 
equivalent of 2 and a grading temperature system $\left(60{ }^{\circ} \mathrm{C}\right.$ for chlorination step and r.t. for fluorination step).

With the optimized conditions in hand, we next examined the substrate scope of sodium sulfonate (Table 2). To be delighted, both the electron-donating (3a, 3c, 3d, 3e) and electron-withdrawing groups (3f) were tolerated with the present strategy, however, the existence of nitro group obviously suppressed the yield (3f, 45\%). It has to be mentioned that the arylsulfonate containing electron withdrawing groups such as 3,5-bis(methoxycarbonyl), 3-cyano and 2-trifluoromethyl failed to generate the corresponding products $(\mathbf{3 k}, \mathbf{3} \mathbf{l}$ and $\mathbf{3 m})$ under this condition. The steric hindrance effect was not obvious, even for trimethyl-substituted sulfonate (3d).

Naphthalene sulfonates were successfully converted to the corresponding SFs with moderate to good yields $(\mathbf{3 g}, \mathbf{3 h})$, but the transformation of naphthalene-1-sulfonate required more catalyst and higher reaction temperature in the chlorination process. Importantly, the synthesized pentane-1-sulfonyl fluoride $(3 \mathbf{j})$ was found to be an efficient inhibitor of lipoprotein lipase. ${ }^{\mathbf{1 4}}$ The potency of the inhibitors decreased as the chain length decreased, ${ }^{\mathbf{1 4}, 17}$ which means nonane-1-sulfonyl fluoride (3i) bearing a longer chain can also be a potential candidate as lipoprotein lipase inhibitor. Moreover, the present strategy shows superior efficiency compared with Kokotos' work ${ }^{\mathbf{1 4}}$ wherein 10-fold molar excess of anhydrous sodium fluoride was required under refluxing acetone.

To evaluate the influence of different cations for the efficiency of this new protocol, a series of sulfonate salts containing various cations were examined. As shown in Table 3, the common sulfonate salts of monovalent potassium, lithium and silver were smoothly converted to 3 a with moderate to good yields (1k-1m). Meanwhile, the nonmetallic sulfonate salts of

Table 2 Substrate scope screening of sodium sulfonate ${ }^{a}$

$\underset{1}{\stackrel{R_{2}}{2}}$

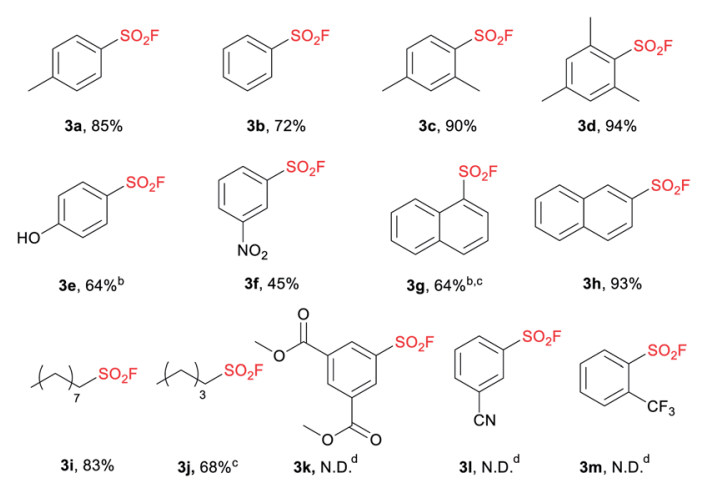

\footnotetext{
${ }^{a}$ General conditions: $1(2.0 \mathrm{mmol}), 2(2.2 \mathrm{mmol})$, TBAB $(32.2 \mathrm{mg}$, $5 \mathrm{~mol} \%$ ), $\mathrm{CH}_{3} \mathrm{CN}\left(10 \mathrm{~mL}, 0.2 \mathrm{M}\right.$ ); $\mathrm{KHF}_{2}$ (468 mg, 3.0 eq.), acetone (10 $\mathrm{mL}, 0.2 \mathrm{M}$ ), isolated yields. ${ }^{b}$ Additional $3 \mathrm{~h}$ at $70{ }^{\circ} \mathrm{C}$ was required after reacting at $60{ }^{\circ} \mathrm{C}$ for $12 \mathrm{~h} .{ }^{c}$ TBAB $(128.8 \mathrm{mg}, 20 \mathrm{~mol} \%) .{ }^{d} \mathrm{ND}=$ not detected.
}

Table 3 Substrate scope screening of sulfonate salts ${ }^{a}$

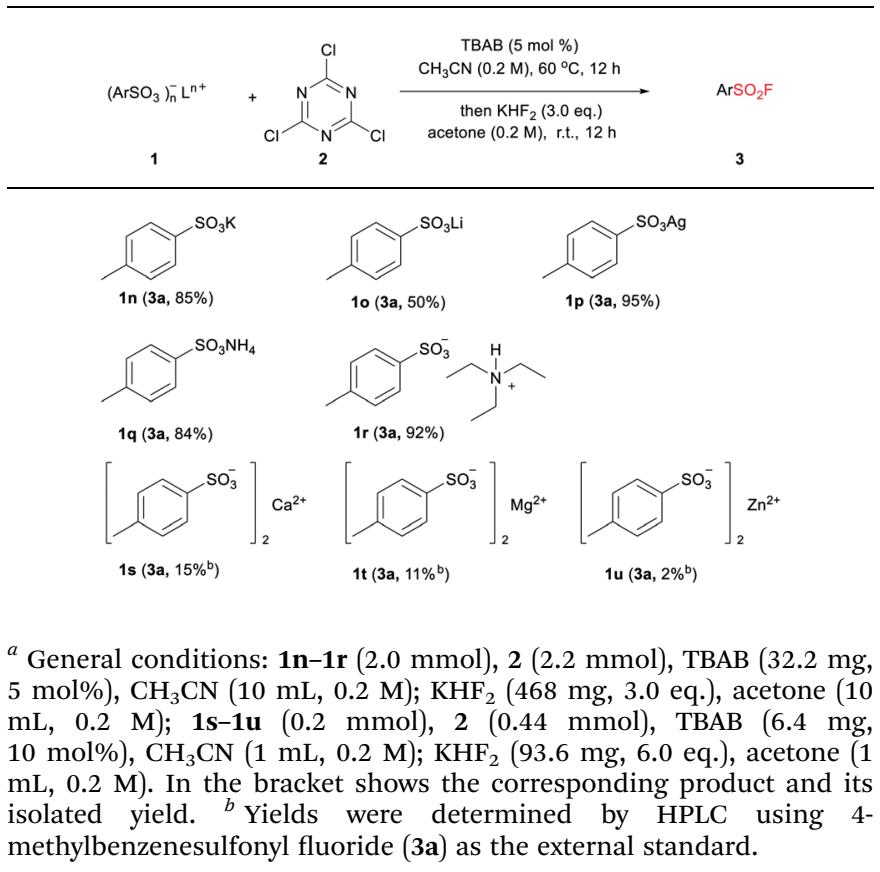

ammonium and tertiary ammonium, patented for internal and external antistatic agents for non-conducting organic materials, ${ }^{18}$ were also successfully transformed to $\mathbf{3 a}$ with good yields (1n, 10). Nevertheless, the sulfonate salts of divalent metals, such as calcium, magnesium and zinc, were only slightly reacted, resulting in poor yields (1p-1r). The lower yields of the corresponding sulfonyl fluorides from the sulfonate salts of divalent metals may be attributed to the stronger coordination ability of the divalent salts comparing to their monovalent conterparties, ${ }^{19}$ and the stronger coordination ability is not favourable for the preliminary formation of arylsulfonyl chlorides prior to generating sulfonyl fluorides.

In our attempt to expand the substrate scope, we observed that TBAB as catalyst was not able to give satisfactory yield of SF from sulfonic acid under standard conditions (the detailed catalyst screening can be found in ESI $\dagger$ ). Upon extensive study, we were pleased to find that the use of $5 \mathrm{~mol} \%$ of tetramethylammonium chloride (TMAC) allowed the transformation of sulfonic acid to the corresponding sulfonyl fluorides effectively and efficiently. As demonstrated in Table 4, a series of aryl SFs bearing electron-donating groups were obtained with moderate to good yields $(\mathbf{3 a}-\mathbf{3 c}, \mathbf{3 e})$. The naphthalene moiety could also be tolerated, achieving a yield of $74 \%(3 \mathbf{~ h})$. Compared with the reported methods, ${ }^{9,20}$ this system shows higher efficiency and mildness, providing a beneficial complement to the current synthetic strategy toward the installation of SF.

In conclusion, we have developed a new transition-metal-free one-pot method for the concise preparation of sulfonyl fluorides from sulfonates or sulfonic acids. The high efficiency and compatibility were demonstrated under mild reaction conditions from readily available and easy-handling reagents. This 
Table 4 Substrate scope screening of sulfonic acid ${ }^{a}$
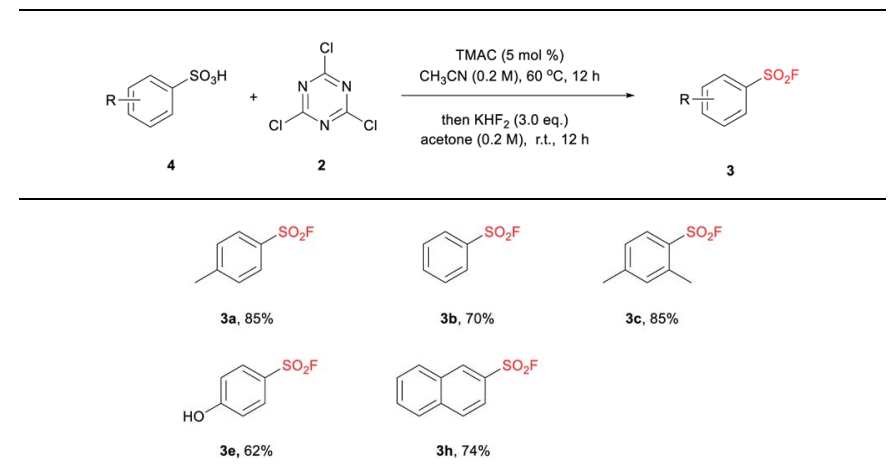
${ }^{a}$ General conditions: $4(2.0 \mathrm{mmol}), 2(2.2 \mathrm{mmol})$, TMAC $(10.9 \mathrm{mg}$,
$5 \mathrm{~mol} \%), \mathrm{CH}_{3} \mathrm{CN}(10 \mathrm{~mL}, 0.2 \mathrm{M})$, then $\mathrm{KHF}_{2}(468 \mathrm{mg}, 3.0 \mathrm{eq}$.$) , acetone$
$(10 \mathrm{~mL}, 0.2 \mathrm{M})$, isolated yields.

new protocol provides a favourable alternative to the current synthetic toolbox for the preparation of diverse SFs.

\section{Conflicts of interest}

There are no conflicts to declare.

\section{Acknowledgements}

We are grateful for financial support from the National Natural Science Foundation of China (Grant No. 21703162, and Grant No. 21772150), the Wuhan Applied Fundamental Research Program of Wuhan Science and Technology Bureau (Grant No. 2017060201010216), the 111 Project (Grant No. B18038) and Wuhan University of Technology.

\section{Notes and references}

1 (a) J. Dong, L. Krasnova, M. G. Finn and K. B. Sharpless, Angew. Chem., Int. Ed., 2014, 53, 9430; (b) P. K. Chinthakindi and P. I. Arvidsson, Eur. J. Org. Chem., 2018, 2018, 3648; (c) T. Abdul Fattah and A. Saeed, J. Fluorine Chem., 2018, 213, 87.

2 (a) A. Narayanan and L. H. Jones, Chem. Sci., 2015, 6, 2650; (b) M. Gehringer and S. A. Laufer, J. Med. Chem., 2018, DOI: 10.1021/acs.jmedchem.8b01153.

3 C. Sadlowski, B. Park, C. A. Borges, S. Das, D. Lucas Kerr, M. He, H. Han, L. Riley and N. Murthy, Mol. Syst. Des. Eng., 2018, 3, 599.

4 (a) N. P. Grimster, S. Connelly, A. Baranczak, J. Dong, L. B. Krasnova, K. B. Sharpless, E. T. Powers, I. A. Wilson and J. W. Kelly, J. Am. Chem. Soc., 2013, 135, 5656; (b) E. C. Hett, H. Xu, K. F. Geoghegan, A. Gopalsamy, R. E. Kyne, C. A. Menard, A. Narayanan, M. D. Parikh, S. Liu, L. Roberts, R. P. Robinson, M. A. Tones and L. H. Jones, ACS Chem. Biol., 2015, 10, 1094; (c) C. Dubiella, H. Cui and M. Groll, Angew. Chem., Int. Ed., 2016, 55, 13330; (d) Q. Zhao, X. Ouyang, X. Wan, K. S. Gajiwala, J. C. Kath, L. H. Jones, A. L. Burlingame and J. Taunton, J.
Am. Chem. Soc., 2017, 139, 680; (e) T. E. J. Chavas, M. J. Fuchter and P. A. DiMaggio, ACS Chem. Biol., 2018, 13, 2897.

5 (a) D. E. Fahrney and A. M. Gold, J. Am. Chem. Soc., 1963, 85, 997; (b) A. E. Annamalai and R. F. Colman, J. Biol. Chem., 1981, 256, 10276; (c) J. C. Powers, J. L. Asgian, Ö. Doğan Ekici and K. E. James, Chem. Rev., 2002, 102, 4639; (d) I. M. Serafimova, M. A. Pufall, S. Krishnan, K. Duda, M. S. Cohen, R. L. Maglathlin, J. M. McFarland, R. M. Miller, M. Frödin and J. Taunton, Nat. Chem. Biol., 2012, 8, 471; (e) D. Manvar, K. Singh and V. N. Pandey, Biochemistry, 2013, 52, 432; (f) H. Mukherjee, J. Debreczeni, J. Breed, S. Tentarelli, B. Aquila, J. E. Dowling, A. Whitty and N. P. Grimster, Org. Biomol. Chem., 2017, 15, 9685.

6 (a) J. A. H. Inkster, K. Liu, S. Ait-Mohand, P. Schaffer, B. Guérin, T. J. Ruth and T. Storr, Chem.-Eur. J., 2012, 18, 11079; (b) L. Matesic, N. A. Wyatt, B. H. Fraser, M. P. Roberts, T. Q. Pham and I. Greguric, J. Org. Chem., 2013, 78, 11262.

7 (a) A. R. Beauglehole, S. P. Baker and P. J. Scammells, J. Med. Chem., 2000, 43, 4973; (b) J. W. Clader, W. Billard, H. Binch III, L.-Y. Chen, G. Crosby Jr, R. A. Duffy, J. Ford, J. A. Kozlowski, J. E. Lachowicz, S. Li, C. Liu, S. W. McCombie, S. Vice, G. Zhou and W. J. Greenlee, Bioorg. Med. Chem., 2004, 12, 319.

8 A. Talko and M. Barbasiewicz, ACS Sustainable Chem. Eng., 2018, 6, 6693.

9 T. A. Bianchi and L. A. Cate, J. Org. Chem., 1977, 42, 2031.

10 (a) A. T. Davies, J. M. Curto, S. W. Bagley and M. C. Willis, Chem. Sci., 2017, 8, 1233; (b) A. L. Tribby, I. Rodríguez, S. Shariffudin and N. D. Ball, J. Org. Chem., 2017, 82, 2294.

11 (a) H.-L. Qin, Q. Zheng, G. A. L. Bare, P. Wu and K. B. Sharpless, Angew. Chem., Int. Ed., 2016, 55, 14155; (b) G.-F. Zha, Q. Zheng, J. Leng, P. Wu, H.-L. Qin and K. B. Sharpless, Angew. Chem., Int. Ed., 2017, 56, 4849; (c) G.-F. Zha, G. Bare, J. Leng, Z.-P. Shang, Z. Luo and H.-L. Qin, Adv. Synth. Catal., 2017, 359, 3237; (d) S.-M. Wang, C. Li, J. Leng, S. N. A. Bukhari and H.-Li. Qin, Org. Chem. Front., 2018, 5, 1411; (e) C. Li, S.-M. Wang and H.-L. Qin, Org. Lett., 2018, 20, 4699; (f) S.-M. Wang, B. Moku, J. Leng and H.-L. Qin, Eur. J. Org. Chem., 2018, 32, 4407; $(g)$ J. Leng and H.-L. Qin, Chem. Commun., 2018, 54, 4477; (h) L. Ravindar, S. N. A. Bukhari, K. P. Rakesh, H. M. Manukumar, H. K. Vivek, N. Mallesha, Z.-Z. Xie and H.-L. Qin, Bioorg. Chem., 2018, 81, 107; (i) G.-F. Zha, S.-M. Wang, K. P. Rakesh, S. N. A. Bukhari, H. M. Manukumar, H. K. Vivek, N. Mallesha and H.-L. Qin, Eur. J. Med. Chem., 2019, 162, 364; (j) X. Zhang, B. Moku, J. Leng, K. P. Rakesh and H.-L. Qin, Eur. J. Org. Chem., 2019, 1763.

12 (a) C. Ni, M. Hu and J. Hu, Chem. Rev., 2015, 115, 765; (b) M. Nonn, L. Kiss, M. Haukka, S. Fustero and F. Fulop, Org. Lett., 2015, 17, 1074; (c) A. G. Beaman and R. K. Robins, J. Am. Chem. Soc., 1961, 83, 4038; (d) S. W. Wright and K. N. Hallstrom, J. Org. Chem., 2006, 71, 1080.

13 M. Kulka, J. Am. Chem. Soc., 1950, 72, 1215. 
14 G. Kokotos, S. Kotsovolou, V. Constantinou-Kokotou, G. Wu and G. Olivecrona, Bioorg. Med. Chem. Lett., 2000, 10, 2803.

15 L. De Luca, G. Giacomelli and A. Procheddu, J. Org. Chem., 2001, 66, 7907.

16 S. Narayan, J. Muldoon, M. G. Finn, V. V. Fokin, H. C. Kolb and K. B. Sharpless, Angew. Chem., Int. Ed., 2005, 44, 3275.

17 D. P. O'Connell, D. F. LeBlanc, D. Cromley, J. Billheimer, D. J. Rader and W. W. Bachovchin, Bioorg. Med. Chem. Lett., 2012, 22, 1397.
18 C. Govindan, US Pat, 5053 531, 1991.

19 F. Horkay, I. Tasaki and P. J. Basser, Biomacromolecules, 2001, 2, 195.

20 (a) V. A. Petrov, S. Swearingen, W. Hong and W. Chris Petersen, J. Fluorine Chem., 2001, 109, 25; (b) J.-G. Kim and D. O. Jang, Synlett, 2010, 20, 3049. 